\title{
História, narrativa e representações da administração pública brasileira ${ }^{1}$
}

Frederico Lustosa da Costa

Universidade Federal Fluminense (UFF)

A invenção da administração pública é um processo de construção e atualização de representações do aparato estatal e de sua interação com a sociedade alimentado por narrativas históricas e imagens simbólicas criadas por intelectuais, homens públicos, tecnocratas e cronistas. Essa invenção também se nutre da compreensão das influências das matrizes políticas, econômicas, sociais, culturais e jurídicas das nossas atuais instituições e práticas administrativas. Trata-se de uma forma de estabelecer a conexão de sentidos entre estruturas, acontecimentos e representações. Nessa direção, este ensaio tem o propósito de apresentar e discutir, de forma breve, os achados e omissões da historiografia recente da administração pública brasileira e as contribuições que a leitura crítica do pensamento social pode oferecer para desfazer mitos sobre essa herança histórica. Seu propósito consiste em examinar, de um ponto de vista crítico, a perspectiva evolucionista da historiografia e a abordagem culturalista do pensamento social que informam análises e diagnósticos sobre a administração pública brasileira.

Palavras-chave: administração pública - Brasil, história, Estado e sociedade

[Artigo recebido em 4 de junho de 2018. Aprovado em 13 de novembro de 2018.]

\footnotetext{
${ }^{1}$ Este trabalho nasceu de uma intervenção no $4^{\circ}$ Congresso de Gestão de Pessoas no Setor Público Paulista, realizado nos dias 21 e 22 de outubro de 2015, em São Paulo, organizado pelo Governo do Estado de São Paulo, onde proferiu palestra sobre o tema "A invenção da administração pública brasileira: história, cultura e direito", em 21 de outubro de 2015. Uma versão mais próxima ao atual desenvolvimento, elaborada em parceria com a prof. Elza Marinho (PPGAd-UFF), intitulada "História e Representações da Administração Pública", foi submetida e aprovada no XLII Encontro da ANPAD - EnANPAD 2018, realizado em Curitiba, de 03 a 06 de outubro de 2018.
} 


\section{Historia, narrativa y representaciones de la administración pública brasileña}

La invención de la Administración Pública es un proceso de construcción y actualización de representaciones del aparato estatal y de su interacción con la sociedad alimentadas por narrativas históricas e imágenes simbólicas creadas por intelectuales, hombres públicos, tecnócratas y cronistas. Esta invención también se nutre de la comprensión de las influencias de las matrices políticas, económicas, sociales, culturales y jurídicas de nuestras actuales instituciones y prácticas administrativas. Es una forma de establecer la conexión de sentidos entre estructuras, acontecimientos y representaciones. En esta perspectiva, este ensayo tiene el propósito de presentar y discutir, de forma breve, los hallazgos y omisiones de la historiografía reciente de la Administración Pública brasileña y las contribuciones que la lectura crítica del pensamiento social puede ofrecer para deshacer mitos sobre esa herencia histórica. Se trata de examinar, desde un punto de vista crítico, la perspectiva evolucionista de la historiografía y el abordaje culturalista del pensamiento social que informan análisis y diagnósticos sobre la administración pública brasileña.

Palabras clave: administración pública - Brasil, historia, Estado y sociedad

\section{History, narrative and representations of the Brazilian public administration}

Public Administration is a invention. It's a process of building and updating of social representations of the state apparatus and its interaction with society supported by historical narratives and symbolic images created by intellectuals, politicians, technocrats and journalists. This invention is also based on the understanding of the influences of the political, economic, social, cultural and legal sources of our current institutions and administrative practices. It is a way of establishing the connection of meanings between structures, events and representations. In this sense, this critical essay has the purpose of presenting and discussing briefly the findings and omissions of the recent historiography of the Brazilian Public Administration and the contributions that the critical reading of Brazilian social thought can offer to undo myths about this historical heritage. It aims critically examining and discussing the evolutionist perspective of historiography and the culturalist approach to social thought that inform analyzes and diagnoses about the Brazilian public administration.

Keywords: public administration - Brazil, history, State and society 


\section{Introdução}

A administração pública brasileira, enquanto instituição e representação, é uma invenção coletiva forjada ao longo do tempo por reconstruções históricas construídas a partir de fragmentos da realidade e por interpretações (de acontecimentos e processos) dominantes que selecionam atos, fatos e narrativas a serem repertoriados.

Examinar e discutir a "invenção" da administração pública brasileira é uma tentativa de, ao mesmo tempo, reconstruir o processo sócio histórico e resgatar as representações sobre o mundo social e político, como formas de encontrar elementos para a compreensão das influências das matrizes políticas, econômicas, sociais, culturais e jurídicas sobre as nossas atuais instituições e práticas administrativas. É buscar a conexão de sentidos entre estruturas, acontecimentos e representações. É colocar em primeiro plano a dinâmica da superestrutura da formação social brasileira.

Dois avanços recentes oferecem elementos úteis a essa empreitada. De um lado, a retomada dos estudos históricos no campo da Administração Pública. Com efeito, os últimos anos têm assistido a um tímido revival da História da Administração Pública, com esforços individuais e iniciativas institucionais que resultam na publicação de estudos e pesquisas, na realização de seminários, encontros e debates e na publicação de importantes monografias e coletâneas. De outro, o continuado esforço de resgate do pensamento social brasileiro, na forma de reedições, reinterpretações e estudos críticos de clássicos da matéria, atualizando a "Teoria do Brasil" e contribuindo para superar as descrições e adjetivações simplistas e anacrônicas. Há, portanto, um rico acervo de conhecimentos que nos ajuda a transitar, de forma mais ou menos segura, nesse universo de acontecimentos, processos sociais, referências, imagens simbólicas (SFEZ, 1988) e representações.

Partindo desses avanços, o presente trabalho tem o propósito de apresentar e discutir, de forma breve, os achados e omissões da historiografia recente da administração pública brasileira e as contribuições que a leitura crítica do pensamento social pode oferecer para desfazer mitos sobre essa herança histórica e cultural. Não se trata de refazer, no breve espaço de um artigo, o panorama (e a interpretação possível) da história administrativa do Brasil, até porque essa tarefa, como os riscos a ela inerentes, já foi intentada (BRESSER PEREIRA, 2001; LUSTOSA DA COSTA, 2008). Trata-se, antes, de apontar nessas narrativas as lacunas, omissões e equívocos cristalizados ao longo dos anos que continuam a informar a compreensão da administração pública brasileira hoje. Por outro lado, ao retomar criticamente as categorias utilizadas para descrever as relações entre o Estado e sociedade, o artigo 
pretende desfazer mitos que informam diagnósticos e propostas de intervenção que não examinam as raízes dos supostos problemas identificados nem tratam as causas das suas manifestações.

Assim, o trabalho está divido em duas partes principais, além desta introdução e das considerações finais, que cumprem esses objetivos complementares. $\mathrm{Na}$ primeira, é feita uma breve apresentação dos avanços e das fragilidades que ainda persistem na historiografia sobre administração pública, chamando a atenção para as principais lições que ela tem nos oferecido nos últimos anos. A segunda apresenta, também de forma breve, quase esquemática, as categorias que têm sido utilizadas para definir o Estado e a administração pública e suas representações, as críticas dirigidas a essas interpretações e os usos e abusos que delas têm sido feitos por reformadores e estudiosos da administração pública no diagnóstico de seus problemas e na indicação de possíveis soluções. As considerações finais apresentam algumas consequências mais gerais dessas percepções que acabam por ter impactos sociais que vão além dos projetos de reforma administrativa.

\section{História e historiografia da administração pública}

Na última década, ao lado de iniciativas mais perenes, como o trabalho continuado do Projeto MAPA (Memória da Administração Pública) do Arquivo Nacional, na esteira da celebração de efemérides, como os 200 anos da transferência da Corte portuguesa para o Rio de Janeiro, surgiram esforços pontuais (mas significativos) que atestam a renovação do interesse pelos estudos históricos no campo da administração pública. Assim, diversas publicações recentes vêm se juntar à vigorosa produção historiográfica que vicejou na área até a década de 1980.

A título de exemplo, basta mencionar a realização, em 2008, do seminário Brasil: 200 anos de Estado, 200 anos de administração pública, uma iniciativa conjunta da Fundação Getúlio Vargas (FGV), da Fundação Casa de Rui Barbosa e do Tribunal de Contas do Município do Rio de Janeiro (TCMRJ), que ofereceu um vasto panorama histórico da evolução da administração pública brasileira e sua historiografia e resultou na publicação do livro de mesmo título (LUSTOSA DA COSTA; ZAMOT, 2010). No ano da publicação dessa primeira coletânea, também foi organizada outra, com objetivos mais modestos, editada por Christina W. Andrews e Edison Bariani, intitulada Administração Pública no Brasil: breve história política, com vários textos de interesse histórico (ANDREWS; BARIANI, 2010). Dois anos depois, foi realizado no Arquivo Geral da Cidade do Rio de Janeiro, por iniciativa do Arquivo Nacional e do Arquivo Público do Estado do Rio de Janeiro, o seminário Estado e administração: perspectivas de pesquisa, que tinha como objetivo discutir a história do Estado e da administração pública brasileira e apresentar os avanços historiográficos na área. 
Esse evento resultou na publicação pelo Arquivo Nacional de um dossiê temático sobre Estado, Poder e Administração na revista Acervo (2012), com textos sobre vários temas e diversos tempos históricos.

Não obstante os significativos resultados verificados nos últimos anos na retomada dos estudos históricos na área da Administração Pública, muito ainda há que ser feito no sentido de incorporar a essa produção historiográfica as principais conquistas da historiografia contemporânea. Com efeito, a maioria dos trabalhos recentes que vieram contribuir para renovação do campo pouco contribuiu para a superação das limitações indicadas pela crítica que se dirigia à monumental História Administrativa do Brasil, iniciada pelo DASP ainda nos anos 1950 (LUSTOSA DA COSTA, 2010, 2016).

De fato, a produção historiográfica sobre a administração pública esteve imune às mudanças de perspectiva teórico-metodológica introduzidas pela História dos Anais e pela Nova História, negligenciando o aporte das ciências sociais, a incorporação de novos objetos, a adoção de temporalidades múltiplas e o uso de fontes alternativas. A história administrativa continuou a se apegar à narrativa de atos e fatos, valorizando os aspectos episódicos e biográficos e a ação individual de líderes e "heróis providencias" - monarcas, tiranos, políticos e dirigentes em geral, caracterizando aquilo que os franceses chamam de história événementielle. Ela se vale das mesmas fontes de documentação escrita, sem se ocupar da estatística descritiva e de outros dados indispensáveis à história serial. Peca ainda pela incapacidade de redefinir seu objeto no sentido de tomá-lo em sua totalidade e apreendê-lo na sua complexidade, enquanto instituição (estruturas), práticas (processos) e representações.

Por outro lado, essa nova concepção histográfica permite conceber o próprio objeto da história administrativa, como representação social, vale dizer

como construção coletiva de um conjunto de imagens simbólicas que introjetam valores e estabelecem predisposições mentais e atitudes reflexivas no trato individual e coletivo com as diversas categorias que dão conta das relações entre o Estado e a Sociedade - cidadania, autoridade, soberania, democracia, etc. Assim, a história do Estado é a história de suas instituições e da apropriação que delas fazem os cidadãos, entre práticas e representações (LUSTOSA DA COSTA, 2010, p. 38).

Talvez a exceção que confirma essa regra seja o já mencionado trabalho desenvolvido pelo Arquivo Nacional por meio do MAPA (Memória da Administração Pública Brasileira), projeto de pesquisa criado em 1981, originalmente voltado para o levantamento da estrutura administrativa colonial, sistematizando "o corpo de 
leis que regulavam a implantação e o funcionamento dos órgãos e cargos instalados na colônia portuguesa na América" (CABRAL, 2011, p. 7), que se converteu em um programa permanente que contempla dados do Império e da República e está disponível como banco de dados on-line (Dicionário da Administração Pública Brasileira on-line - http://linux.an.gov.br/mapa/?p=1181).

Em todo caso, a velha tradição narrativa que começa com Varnhagen (1956), passa por Fleiuss (1922) e se completa com a coleção da História Administrativa do Brasil do Dasp-Funcep, as grandes sínteses interpretativas sobre o coronelismo (LEAL, 1997; QUEIROZ, 1976), o patrimonialismo (FAORO, 2001) e o formalismo (GUERREIRO RAMOS, 1983), os trabalhos de alguns brasilianistas (BETHEL 1985; GRAHAM, 1997; MORSE, 1988) e as monografias temáticas de cientistas sociais (URICOECHEA, 1978; QUEIROZ, 1976; WEFFORT, 1978; SCHWARTZMAN, 1988) e historiadores (CARVALHO, 1982; CASTRO GOMES, 1988; DOLHNIKOFF, 2005; LESSA, 1999; MARTINS, 2007; ROHLOFF DE MATTOS, 1999; WEHLING, 2004)², ao apresentarem sua seleção de atos, fatos e processos de peso, também oferecem alguns achados e ensinamentos que parecem estar sendo negligenciados pelas sínteses mais apressadas que estudiosos da administração pública têm empreendido na busca de contextualizar a discussão sobre a reforma do Estado, por exemplo. Tais constatações podem ser resumidas nas seguintes assertivas.

\section{A administração pública brasileira é um organismo complexo, multifacetado} e polimorfo. É o Estado em ação, manifestando-se por meio de seus poderes coercitivos em inúmeros domínios. Como instituição (estrutura), burocracia (corpo de funcionários) e processo (ação gerencial), contempla um vasto conjunto de órgãos e atividades que se ocupam dos mais variados aspectos da vida social. Não pode, portanto, ser examinada como um todo monolítico, com atuação simétrica e uniforme. Sua história deve dar conta de transformações que ocorrem em todas essas dimensões. Trata-se de trazer para os estudos de Administração Pública a noção de história total, que dá conta da complexidade do fenômeno e das suas conexões com os diversos domínios da atividade humana.

2. Apesar da constatação de Varnhagen $(1956)^{3}$, sempre citada como exemplo de formalismo na organização governamental da Coroa portuguesa no Rio de

\footnotetext{
${ }^{2}$ Um excelente panorama da historiografia no campo da administração pública foi feito por Lúcia Guimarães (2010) em seus "Breves apontamentos para a história da administração pública o Brasil”.

3 "O Marquês de Aguiar parece ter começado por consultar o almanaque de Lisboa e à vista dele ter-se proposto a satisfazer a grande comissão que o Príncipe lhe delegara, transplantando para o Brasil, com seus nomes próprios e empregados (para não falar de vícios e abusos), toas as instituições que lá havia as quais se reduziram a muitas juntas e tribunais que mais serviam de peias que de auxílio à administração, sem meter em conta o muito que aumentou as despesas públicas, e o ter-se visto obrigado a empregar um sem-número de nulidades, pelas exigências de uma chusma de fidalgos que haviam emigrado da metrópole" (VARNHAGEN, 1956, p. 94).
} 
Janeiro, o Estado brasileiro não é e, provavelmente, nunca foi mero espelho do Estado português. Embora D. João VI tenha implantado na nova sede da monarquia a estrutura dos ministérios e o plano de cargos listados no Almanaque de Lisboa, uma realidade institucional nunca pode ser inteiramente transplantada de um meio social para outro. De acordo com Dilma Cabral (2011, p. 12-14), diferentes condições objetivas contribuem para o surgimento de novos desenhos institucionais, conformados pela adaptação do modelo importado à realidade do país nascente. Em pouco tempo, várias instâncias que articulavam as relações entre a Metrópole lisboeta e administração colonial no Rio de Janeiro se revelaram desnecessárias. Por outro lado, logo também surgiram novas necessidades que ensejaram a criação de instituições inexistentes na antiga sede da monarquia. Ao longo do século 19 , as diferenças entre a organização da monarquia portuguesa, que também se diferenciava internamente, e a estrutura do governo do Império brasileiro só aumentaram, de sorte que o estabelecimento de paralelos e simetrias entre os dois países ficou cada vez mais difícil, prejudicando as comparações (simplificadoras) associadas à herança ibérica.

3. A história do Estado brasileiro não começa com a Revolução de 1930. Ela tem antecedentes na colônia e seu ponto inaugural, do ponto de vista deste artigo, é a chegada da Família Real portuguesa ao Rio de Janeiro, em 1808, que configura a "inversão metropolitana", quer dizer, a condução do aparelho de Estado português a partir do Brasil, que assume as funções de metrópole e, consequentemente, de Estado nacional. Não obstante o Primeiro Governo Vargas ter constituído um marco importante na modernização e na burocratização da máquina pública, as mudanças que implementou não surgiram de uma hora para outra. Só para dar um exemplo, basta lembrar que, desde o Império, havia precedentes importantes relacionados com o recrutamento e a organização de carreiras dos ministérios do Exército e da Fazenda (Carvalho, 1996, pp. 137-156). Já na República Velha, a organização da carreira diplomática no Itamaraty antecipava a introdução do sistema de mérito que virá a ser intentada em todo governo a partir de 1936 (FARIAS, 2018). Portanto, além de transformações políticas e institucionais importantes, como a abdicação de D. Pedro I, a mudança no sistema regencial, o Ato Adicional e sua posterior reinterpretação, a maioridade de D. Pedro I, a adoção do semiparlamentarismo e a própria Proclamação da República, que tiveram impacto na organização governamental e na dinâmica da gestão pública, mudanças pontuais em vários setores descartam a hipótese do imobilismo histórico que teria caracterizado o patrimonialismo do Império e da República Velha.

4. A visão evolucionista da administração pública brasileira é simplificadora e equívoca. A ideia de que a máquina pública viveu um processo evolutivo que 
passou pelas etapas da administração patrimonial, da administração burocrática e da administração gerencial se cristalizou e popularizou a partir da edição do Plano Diretor da Reforma do Aparelho do Estado (MARE, 1995). Nesse documento, o então ministro Bresser Pereira justapôs, em sequência, três tipos de administração pública, procedendo à identificação da administração imperial como a estrutura patrimonialista definida por Faoro (2001); à descrição do modelo prescritivo propugnado pela reforma administrativa do Primeiro Governo Vargas, caracterizado por Beatriz Wahrlich (1974) como burocrático; e à apresentação de seu próprio modelo, que teria antecedentes na reforma tecnocrática de 1967 (Decreto-lei $n^{\circ}$ 200), mas que está fortemente ancorado na Nova Gestão Pública, definido como gerencial (MARE, 1995). Mais tarde, essa concepção foi bastante refinada em uma apresentação de um modelo assumidamente evolutivo, mais referenciado em interpretações do pensamento social do que em evidências históricas, que vai do Estado patrimonial ao gerencial (BRESSER PEREIRA, 2001).

O modelo de Bresser Pereira leva a uma concepção das transformações do Estado como um processo de modernização, que estabelece uma sequência de categorias que assumem as características de um modelo evolutivo para formas mais racionais de administração pública. Os três estágios do desenvolvimento da administração pública brasileira não constituem tipos ideais, mas etapas históricas que se apresentam de forma linear, sem sobreposições, deixando de considerar a permanência e a convivência entre novas e velhas formas (PINHO, 1998). Na Administração Burocrática, a partir da era Vargas, os traços patrimonialistas desaparecem e o esquema assume um caráter voluntarista que aponta para o fim da História da Administração Pública, com o advento da Administração Gerencial.

5. A perspectiva evolucionista, ao segmentar e uniformizar etapas históricas, pode favorecer o pecado do anacronismo, que consiste em utilizar conceitos e ideias de uma época para analisar os fatos de outro tempo. Em outras palavras, é a intrusão de uma época em outra, quando se tenta avaliar um determinado tempo histórico à luz de valores que não pertenciam a esse mesmo tempo (FEBVRE, 1953). Por isso, é imprescindível que o historiador evite transplantar dados, valores e concepções da atualidade ou de tempos recentes que não existiam no período estudado. Por exemplo, ao apresentar o modelo de administração patrimonialista, Bresser Pereira afirma que "a corrupção e o nepotismo são inerentes a esse tipo de administração" (MARE, 1995, p. 15), quando se sabe que a apropriação de rendas pela prestação de serviços públicos e a nomeação de parentes não constituem distorções, mas sim características do patrimonialismo. 


\section{Representações de representações}

O chamado Pensamento Social Brasileiro, que reúne as obras dos autores considerados como grandes intérpretes brasileiros, tem se constituído numa usina de representações sobre o mundo social e político do país. São categorias, análises e interpretações que têm sido utilizadas para compreender o processo brasileiro, as relações entre o Estado e sociedade e o próprio funcionamento da administração pública.

Nos últimos anos, multiplicaram-se os núcleos de pesquisa, simpósios temáticos e grupos de trabalho que se ocupam de discutir, de diferentes perspectivas, algumas bastante originais (SOUZA, 2015), os clássicos consagrados e alguns autores "novos" que pedem ingresso no panteão dos intérpretes do Brasil. Por outro lado, a incorporação da abordagem da colonialidade e dos estudos pós-colonias ao contexto do pensamento social, cabendo destacar nesse contexto o resgate da obra de Guerreiro Ramos (FILGUeIRAS, 2012; CADERNo CRH, 2015; CADERNOS EBAPE. BR, 2015), ampliou as possibilidades de leitura e revisão crítica de autores e temas excluídos ou engessados em velhas matrizes interpretativas. Além disso, na área de Administração em geral e no campo específico da Administração Pública, cresce o interesse pela contextualização de conceitos e categorias que definem etapas, características ou "mazelas" do nosso aparelho do Estado, como é o caso dos trabalhos de Bresser Pereira (2001) e Lustosa da Costa (2009).

Conforme já assinalado em um primeiro esforço na tentativa de identificar essas influências, a maioria dos intérpretes do Brasil tem

salientado que as raízes do nosso atraso, subdesenvolvimento, dependência, modernização periférica ou inserção pouco competitiva no mundo globalizado, estão plantadas na nossa formação histórica, gerando uma série de determinantes que condicionam o sistema político, o Estado e suas relações com a Sociedade e a Economia. Essas peculiaridades constituem modos de ser, proceder ou pensar que caracterizam nossas instituições, relações sociais e representações do mundo social e político (LUSTOSA DA COSTA, 2009).

Assim, ao propor determinados diagnósticos para as nossas patologias, a formulação dessas categorias "científicas" veicula determinadas representações sociais que informam julgamentos sobre o Estado e a administração pública nem sempre assumidos pelos seus autores, pelo menos, conscientemente. Sua recepção (acrítica) e seu uso cotidiano (como palavras de ordem) acabam por convertê-las em representações de representações, muitas vezes invertendo o sinal da operação simbólica (SFEZ, 1988). 
Não cabe aqui apresentar de forma detalhada os clássicos do pensamento social sobre essas categorias nem repertoriar as críticas que lhes têm sido dirigidas, sobretudo nos últimos anos. O sentido de recuperá-las, de forma bastante breve, é mostrar como o seu uso pelo discurso da modernização administrativa pode informar políticas que ignoram contexto e problemas, reforçam distorções ou atuam apenas sobre efeitos dos supostos males que pretendem enfrentar.

Vasta coleção de escritos tem se debruçado sobre os "ismos" que definem "distorções" ou "mazelas" que caracterizam aspectos da realidade social e política do país, vale dizer, de suas instituições governamentais, que estariam na origem da reduzida efetividade da ação pública no Brasil. Essas "patologias" podem ser agrupadas em principais - patrimonialismo, mandonismo e personalismo - e acessórias - clientelismo ${ }^{4}$, nepotismo, cartorialismo, formalismo, coronelismo e autoritarismo -, podendo se combinar de diversas maneiras. A maioria dessas categorias tem suas matrizes teóricas apoiadas no patrimonialismo, como se verá a seguir.

Nesta seção, a ideia é apresentar, de forma muito breve as três principais categorias e suas eventuais vinculações ou ramificações com categorias secundárias, apontar as principais críticas repertoriadas pela literatura e indicar suas consequências para as políticas de gestão pública e modernização administrativa.

O conceito de patrimonialismo chegou às ciências sociais brasileiras pelas mãos de Sérgio Buarque de Holanda em seu clássico Raízes do Brasil, publicado pela primeira vez em 1936. Ele aparece, de forma bastante breve, no contexto da discussão sobre o "homem cordial", este temperamento ibérico movido por paixões irracionais. Tomando como referência indireta as categorias weberianas, o patrimonialismo é definido em termos bastante simples para se referir à dificuldade dos detentores das posições públicas de responsabilidade em "compreenderem a distinção fundamental entre os domínios do privado e do público" (BUARQUE DE HoLANDA, 2006, p. 159). Segundo o autor

Para o "funcionário patrimonial", a própria gestão política apresentase como assunto de seu interesse particular; as funções, os empregos e os benefícios que deles auferem relacionam-se a direitos pessoais do funcionário e não a interesses objetivos, como sucede no verdadeiro Estado burocrático, em que prevalecem a especialização das funções e o esforço para se assegurarem garantias jurídicas aos cidadãos (BUARQUE DE HOLANDA, 2006, p. 159).

\footnotetext{
${ }^{4}$ Embora o clientelismo possa ser considerado uma categoria muito importante da sociologia política, para os propósitos deste trabalho, ele aparece como manifestação mais frequente de práticas políticas patrimonialistas vinculadas ao mandonismo local.
} 
No Estado patrimonial, a escolha para as funções públicas faz-se com base na confiança pessoal e não nas capacidades dos candidatos. Embora esse corpo de funcionários patrimoniais possa assumir feições burocráticas, falta-lhe a objetividade e a impessoalidade que caracterizam a burocracia.

A tese do patrimonialismo na vida brasileira vai ser aprofundada e discutida por Raymundo Faoro (2001), de forma bastante minuciosa, em Os donos do poder, outro clássico das interpretações do Brasil. Faoro vai buscar as raízes do patrimonialismo na formação do Estado português, cuja monarquia, não tendo se formado com o apoio da nobreza territorial, vai constituir seu quadro administrativo com um estamento de letrados que viria a se converter em uma nobreza burocrática. Esse sistema de dominação teria migrado para o Brasil com a colonização, formando-se aqui um patronato político que, por delegação do Rei e, mais tarde, do Imperador, permitia aos membros do estamento se apropriarem das funções públicas para auferirem rendas. A lógica da política patrimonialista, onde, acredita Faoro, há a autonomia ou mesmo a prevalência da dimensão político-institucional sobre a dinâmica do processo econômico, persistiria na República Velha e deixaria sua herança indelével em toda história republicana. A primazia do poder público fazia com que o nascimento das instituições precedesse o desenvolvimento e as necessidades do processo social, a fim de moldar-lhe a dinâmica e o sentido. O mesmo tipo de burocracia patrimonial que comandava a Corte e dominava a Colônia constituiu a base do Estado brasileiro, do Império à República Velha, dos ciclos extrativistas à rotina mercantil do modelo agroexportador.

$\mathrm{Na}$ perspectiva de Faoro (2001), o patrimonialismo brasileiro absorveu o capitalismo e promoveu o seu desenvolvimento sob comando político, aproveitando dele as técnicas, a indústria, as empresas e os grandes mercados, mas conservando as concessões e privilégios. Seu raciocínio leva a acreditar que, sob o pulso estatal, o estamento "intervencionista", visando conservar privilégios e extrair vantagens, inventou o capitalismo à brasileira, no qual, muitas vezes, o cartório e o favor substituiriam o risco.

Ao longo dos anos, sobretudo a partir da publicação da segunda edição em 1973, o trabalho de Faoro (2001) encontrou crescente acolhida nos meios intelectuais brasileiros, influenciando significativamente trabalhos orientados pela mesma perspectiva (SCHWARTZMAN, 1988) ou outras vertentes de análise que privilegiam categorias de certa forma derivadas do patrimonialismo, como o personalismo ou "pessoalidade" (DAMATTA, 1980). Mesmo mais recentemente, embora reconheça fragilidades históricas na análise do período imperial e também faça restrições à indicação de um caráter unidimensional e vertical da dominação patrimonial, Fernando Henrique Cardoso acredita na persistência da força e do protagonismo 
do estamento, ainda que atenuados pelo fortalecimento da sociedade civil e pela influência das "forças do mercado" (CARDoso, 2013).

Embora o trabalho de Faoro (2001) continue a ser referência básica no pensamento social brasileiro, também é crescente o número de críticas a ele dirigidas. Elas podem ser resumidas nos seguintes pontos:

- uso inadequado e distorcido de categorias weberianas, uma vez que o patrimonialismo de Faoro não se insere em nenhuma das inúmeras variedades de dominação tradicional ou mesmo de formas híbridas como o "patrimonialismo burocrático";

- inexistência de estudos aprofundados sobre a manifestação do fenômeno, pelo menos em igual intensidade, na Monarquia e na República portuguesa, de onde o Brasil teria herdado as instituições políticas e administrativas e as práticas sociais;

- fragilidade da noção de estamento, que ignora a estratificação social dentro da máquina pública, fazendo com que ora possa se referir à classe política, ora à elite do funcionalismo, ora ao corpo burocrático como um todo;

- imobilismo histórico que negligencia transformações institucionais importantes que aconteceram na história do Brasil, cabendo mencionar apenas, entre tantas outras, a Independência e a Proclamação da República.

O patrimonialismo aparece muitas vezes vinculado ao cartorialimo e ao nepotismo. O cartorialismo se refere ao conceito de Estado cartorial, cunhado por Hélio Jaguaribe. Toma como referência o funcionamento dos cartórios, como uma concessão estatal, para identificar um Estado em que as funções públicas, embora se apresentem como serviços públicos de interesse da coletividade, são concebidas e utilizadas para manipular clientelas e perpetuar privilégios, assegurando concessões, empregos e vantagens a determinadas pessoas e grupos. Ou seja, nessa concepção, na qual viceja a regulamentação excessiva, abre-se espaço para o particularismo, a política de clientela, o favor e o privilégio (JAGUARIBE, 2013, p. 54).

Já o nepotismo consiste no favorecimento do parentesco nas relações de trabalho ou emprego. É o recrutamento personalista de parentes em detrimento da avaliação de mérito para o exercício da função pública. O nepotismo contraria o princípio constitucional da impessoalidade, uma vez que institui privilégios em função de relações de parentesco e desconsidera a capacidade técnica para o exercício do cargo público (AIKıN, 1986).

$\mathrm{Na}$ literatura sobre administração pública e, particularmente, nos trabalhos sobre reforma administrativa, o conceito de patrimonialismo é utilizado na sua formulação mais simples como "apropriação do público pelo privado", que leva, 
muitas vezes, a confundi-lo com a corrupção, que é a apropriação de vantagem ilícita pelo exercício de uma função. Patrimonialismo e corrução não se confundem, pois esta última existe em todos os países do mundo, inclusive aqueles que não passaram por nenhuma espécie de patrimonialismo, e é muito comum no universo das empresas privadas.

Apresar das críticas, das derivações para outras categorias e do simplismo interpretativo, a noção de patrimonialismo segue sendo uma referência importante para os estudos de administração pública brasileira e para a construção de sua história. Como desdobramento das teorias de modernização, também informa grande parte dos estudos sobre corrupção (FILGUEIRAS, 2008; OLIVEIRA JÚNIOR et al., 2016).

Seu uso e abuso trazem pelo menos três consequências importantes para a construção de políticas reformistas. A primeira se refere ao sentido liberal privatista implícito na tese do patrimonialismo e largamente aceito pelos reformadores. Se não é possível suprimir do Estado o patrimonialismo deformador, então é preciso minimizar os seus efeitos. O problema deixa de ser as formas de apropriação dos bens públicos por uma elite parasitária, que está mais fora do que dentro do aparelho do Estado, para se constituir no próprio Estado. Se o Estado é o problema, é necessário, pelo menos, tentar diminuir o tamanho do problema. Essa tese antipatrimonialista se traduz não só em formas difusas de criminalização da política e da ação dos servidores públicos (até de professores), mas também, sobretudo, em privatizações, eliminação de programas sociais, redução da força de trabalho e dos direitos dos funcionários públicos. Em resumo, quanto menos Estado, mais prosperidade.

A segunda consequência, decorrente da primeira, é a tendência a identificar o conjunto dos servidores públicos como responsáveis pela suposta "apropriação indevida do público pelo privado" e demonizá-los. Muitas vezes, funcionários humildes são culpados dos males decorrentes da ação corporativista das categorias mais bem organizadas e bem remuneradas, como já aconteceu na campanha presidencial de 1989, quando Collor de Mello elegeu os marajás do serviço público como o inimigo número um a ser vencido (LUSTOSA DA COSTA, 1989). Os marajás, vale dizer, os servidores públicos, são o "novo" nome do "estamento" burocrático.

Finalmente, o terceiro resultado do diagnóstico do patrimonialismo é excessiva simplificação da análise dos problemas da administração pública brasileira, situados entre os resquícios do patrimonialismo (e sua filha dileta, a corrupção) e o excesso de burocracia. Essa visão subtrai a dimensão política da ação do setor público e elide o conflito distributivo a ela inerente. O foco no combate à corrupção coloca em segundo plano os problemas relacionados com a pobreza, a desigualdade e a precariedade dos serviços sociais consagrados como direitos constitucionais. 


\section{Mandonismo}

Outra categoria importante que tem sido utilizada para caracterizar as relações entre o Estado e a sociedade no Brasil é o mandonismo e sua principal variante, o coronelismo. Trata-se de um sistema político caracterizado pela existência local de estruturas oligárquicas e personalizadas de poder. Baseado no controle de algum recurso estratégico, como a terra, por exemplo, ou de outras estruturas de poder, o mandão exerce sobre a população um domínio pessoal e arbitrário que a impede de ter livre acesso ao mercado e à sociedade política. Na história brasileira, sobretudo a partir do segundo Império, o coronelismo se apresentou como uma quase-institucionalização desse sistema de poder.

Embora a face caricata do coronel, com suas grandes glebas de terra, seu gado visto por binóculos da varanda das casas de fazenda, seus blusões de linho e suas alpercatas, muitos chefes políticos locais continuam a adotar práticas de mandonismo, associando patrimonialismo e personalismo, para colocar a máquina pública a serviço de seus projetos de poder. Isso aconteceu no século passado e até recentemente em diferentes quadrantes do território nacional, inclusive no governo local da capital da República.

Vinculado ao patrimonialismo e ao mandonismo, o clientelismo indica um tipo de relação entre atores políticos que envolve concessão de benefícios públicos, na forma de empregos, benefícios fiscais, isenções, em troca de apoio político, sobretudo na forma de voto. A administração pública é instrumentalizada para fins políticos de curto prazo, prestando atendimento segundo critérios de troca de favores com a clientela. De servidora da res publica, torna-se servidora de objetivos voluntaristas dos dirigentes de plantão.

Os conceitos de mandonismo, coronelismo e clientelismo são mais objeto de confusões do que de críticas (CARVALHo, 1997). Muitas vezes, um é tomado pelos outros, prejudicando a precisão indispensável à análise sociológica dos fenômenos a que se referem. $\mathrm{O}$ que se discute é se é pertinente designar como mandonismo ou coronelismo as manifestações de autoritarismo, clientelismo e corrupção que se verificam no exercício do poder local.

Aceitando-se ou não a validade na aplicação dos conceitos, existem evidências de abusos na administração municipal, concernentes ao exercício do poder de polícia, ao protecionismo de grupos preferenciais e à apropriação de vantagens indevidas.

Essa constatação desperta o ímpeto controlador dos reformistas apressados. $\mathrm{Na}$ ânsia de conter a ação nefasta de mandões locais, favorecem políticas centralizadoras que inibem a capacidade de autogoverno das populações locais. O centralismo e os controles centralizados sufocam a administração municipal, reduzindo a autonomia 
dos políticos eleitos e dos dirigentes públicos. As políticas reformistas deixam de apostar na descentralização e no controle social por parte das populações locais. Na verdade, a centralização não está a serviço do desmantelamento das estruturas do mandonismo e do empoderamento das comunidades locais, mas do fortalecimento das estruturas burocráticas de controle.

\section{Personalismo}

A versão mais moderna do conceito de personalismo foi introduzida no pensamento social brasileiro por Roberto DaMatta (1980), em seu clássico Carnavais, malandro e heróis. Segundo o autor, trata-se de uma forma de hierarquizar pessoas, segundo a posse de maior ou menor estoque de capital de relações pessoais, distinguindo indivíduos (os despossuídos) de pessoas (os "enturmados"). Roberto DaMatta tem explorado as possibilidades de compreensão do Brasil como uma sociedade relacional extremamente hierarquizada, a partir da análise de seus rituais.

Segundo sua perspectiva de análise, no universo das relações pessoais, a lei não é a expressão da ordem igualitária, mas sim uma sanção generalizada, da qual só escapam aqueles que conseguem flexibilizar a sua vigência pela "especificidade do caso". Quem se apresenta como "indivíduo" não é um cidadão completo; é um "zéninguém", uma "não-pessoa", alguém que não possui uma "identidade" que possa ser hierarquizada numa escala relacional - filho do presidente, amigo do senador, irmão do desembargador, motorista do governador.

Esse "indivíduo", para quem está dos dois lados do balcão da burocracia pública, não é percebido como o patrão, o cliente e a própria razão de ser do Estado e dos serviços públicos. É um incômodo, um estorvo. No terreno fertilizado por essa mentalidade estão plantadas as raízes de práticas relacionais como o "jeitinho" (VIEIRA; LUSTOSA DA COSTA; BARBOSA, 1982; e, mais recentemente, BARBOSA, 1992) e o "Você-sabe-com-quem-está-falando?".

Em oposição ao princípio constitucional da impessoalidade, admite-se que a administração pública atue de maneira "personalizada" para algumas pessoas, que podem reivindicar um tratamento "diferenciado", e de maneira impessoal para com os indivíduos em geral. Na sociedade relacional, requisitos do domínio racionallegal, ou seja, os elementos que conferem racionalidade e legitimidade à dominação burocrática, como a igualdade perante a lei, a universalidade na aplicação da norma e o princípio da isonomia, estão sujeitos à hierarquização social que distingue "indivíduos" e "pessoas" e posiciona os seus membros de acordo com o peso de seus relacionamentos. 
Associada ao patrimonialismo, ao cartorialismo e ao personalismo está a noção de formalismo. Ela diz respeito ao distanciamento entre as normas prescritas legalmente e as atitudes concretas adotadas quando de sua real implementação. Ocorre quando a não observação da norma não implica na obrigatoriedade de sanções para os infratores (RIGGS, 1964). No Brasil, dizia-se antigamente que "lei é como vacina - umas pegam outras não". Isso quer dizer pegam para uns; para outros, não. Roberto DaMatta (1980, p. 184) acredita que, "por termos leis geralmente drásticas e impossíveis de serem rigorosamente acatadas, acabamos por não cumprir a lei", surgindo manifestações como o "jeitinho", o "Você sabe com quem está falando?" e "outras formas mais autoritárias que facilitam e permitem pular a lei ou nela abrir uma honrosa exceção que a confirma socialmente".

Vieira, Lustosa da Costa e Barbosa (1982) acreditam que esses escapismos acabam por gerar desconfiança com relação às regras universalizantes e atualizar a vigência do formalismo, quer dizer, a discrepância entre as normas prescritas legalmente e o comportamento efetivo dos sujeitos. Já para Guerreiro Ramos (1983), o formalismo pode ser visto também como a expressão de um ideal de sociedade e, portanto, como uma estratégia de mudança social.

O contraponto do personalismo é a separação entre política e administração e a neutralidade burocrática. Acredita-se que os servidores públicos são ou devem ser neutros, sem nenhuma espécie de engajamento. Na verdade, burocratas e administradores fazem política o tempo todo. O exercício do poder discricionário se traduz em atos políticos que trazem consequências para a distribuição dos benefícios. A administração pública não pode funcionar baseada na crença da competência neutra e fechar os olhos para a seletividade. Não se pode substituir o personalismo por uma burocracia fria e insensível, supostamente apoiada na impessoalidade, que é sempre seletiva. Ou seja, a superação da dimensão relacional da hierarquização social não implica automaticamente na eliminação da seletividade do poder discricionário do burocrata "impessoal".

Todas essas categorias disseminadas pelos intérpretes do Brasil têm sido apropriadas de forma acrítica por estudiosos e reformadores para produzir inferências e informar diagnósticos sobre a administração pública brasileira. Infelizmente, a descontextualização dessas interpretações não permite examinálas também como representações sociais, com suas partes de realidade, senso comum e ideologia. 


\section{Considerações finais}

A perspectiva evolucionista e a interpretação culturalista, com a persistência no uso de categorias depreciativas para subsidiar as análises, diagnósticos e propostas de reformas na administração pública brasileira parecem sugerir que o Estado brasileiro, promotor de "hierarquizações", é imutável e está condenado a ensejar a repetição de políticas públicas, práticas de gestão e ações de governo que favorecem grupos preferenciais em detrimento da maioria da população. Essa percepção leva a uma atitude estatofóbica, que só vê solução para os problemas nacionais em um liberalismo simplista e tacanho. Pensar na existência dessas "disfunções" leva a acreditar que tudo que não dá certo se deve à presença do Estado na vida econômica e social. Ou seja, leva a difundir a crença de que onde e quando o Estado intervém tudo se deteriora.

Na verdade, o Estado brasileiro tem sido indutor do desenvolvimento e redutor de assimetrias sociais. A partir do Primeiro Governo Vargas, o Brasil empreendeu um enorme esforço de modernização, inclusive de suas instituições públicas. Sob a regência do Estado, o desenvolvimento econômico baseado no processo de industrialização pela substituição de importações permitiu a superação do modelo agroexportador em declínio, a constituição de uma sociedade urbano-industrial, a criação das estruturas de proteção e seguridade social e a organização política pluralizada de vários segmentos sociais.

A ação estatal criou as condições para que se estabelecesse um mercado onde os diversos agentes econômicos pudessem movimentar-se em liberdade. A esfera pública ampliou-se para criar os espaços de domínio privado. Na medida em que constituiu um setor público dos mais equipados e eficientes do Terceiro Mundo, o Estado brasileiro foi moderno e modernizador.

Por outro lado, a imagem do país construída a partir de distorções e patologias alimenta entre os brasileiros aquilo que o dramaturgo Nelson Rodrigues chamou de "complexo de vira-latas", a ideia de que somos o último entre os povos, comparados a um cão sarnento, digno da piedade das grandes nações do mundo. Os brasileiros acabam por ver com pessimismo as tentativas de compreensão da nossa realidade. A conclusão é sempre a mesma - o Brasil não dá certo. O Brasil não tem jeito.

O Brasil vive uma crise sem precedentes, mas certamente tem enormes vantagens comparativas para reencontrar o caminho do desenvolvimento sustentado e sustentável. Tem grandes perspectivas econômicas e possibilidades de oferecer a seu povo condições materiais para construir uma sociedade justa, equilibrada e democrática. 
A análise dessas representações deve contribuir para que não se perca a perspectiva do que elas realmente são. Representações. Cabe aos intelectuais, tecnocratas e homens públicos fazerem girar a roda da história. Entre instituições, práticas e representações.

\section{Referências bibliográficas}

AIKIN, Charles. Nepotismo. In: Dicionário de Ciências Sociais. Rio de Janeiro: Fundação Getúlio Vargas, 1986.

ANDREWS, Christina W.; BARIANI, Edison (Orgs.). Administração pública no Brasil. São Paulo: Editora Unifesp, 2010.

BARBosA, Lívia. O jeitinho brasileiro: a arte de ser mais igual do que os outros. Rio de Janeiro: Campus, 1992.

Bethel, Leslie (ed.). The Cambridge History of Latina America. Cambridge (UK): Press University of Cambridge, 1985.

Bethel, leslie; Carvalho, José Murilo de. Do Estado Bethel, Brasil from teh Independence to Middle of the Ninetennth Century. In: BETHEL, LeSLIE (ed.). The Cambridge History of Latina America. Cambridge (UK): Press University of Cambridge, 1985,

BReSSer PereIRA, Luís Carlos. Do Estado patrimonial ao gerencial. In: PINHEIRo, Paulo Sérgio; WILHEIM, Jorge; SACHS, Ignacy (Orgs.). Brasil: um século de transformações. São Paulo: Companhia das Letras, 2001.

BRESSER PereIRA, Luiz Carlos. A reforma do Estado dos anos 90: lógica e mecanismos de controle. Lua Nova, São Paulo, n. 45, p. 49-95, 1998. Disponível em: http://www. scielo.br/scielo.php?script=sci_arttext\&pid=S0102-64451998000300004\&lng=en\& nrm=iso>. http://dx.doi.org/10.1590/S0102-64451998000300004. Acesso em: 16 mai. 2018.

BRESSER PEREIRA, Luís Carlos; SPINK, Peter (Orgs.). Reforma do Estado e administração pública gerencial. Rio de Janeiro: Fundação Getúlio Vargas, 1998.

BuARQue de Holanda, Sérgio. Raízes do Brasil. São Paulo: Companhia das Letras, 2006. CABRAL, Dilma. Fontes para uma história política-institucional: a experiência do Arquivo Nacional e a memória da administração pública brasileira. In: SIMPÓsıO NACIONAL DE HISTÓRIA - ANPUH, 26., 2011, São Paulo. Anais... São Paulo: ANPUH, 2011.

CABral, Dilma; CAMARgo, Angélica R. Estado e administração: a corte joanina no Brasil. Rio de Janeiro: Arquivo Nacional, 2010.

Caderno CRH. Salvador, vol. 28, no.73, jan./abr. 2015

CADERNOS EBAPE.BR. Rio de Janeiro: Fundação Getúlio Vargas, v. 13, Edição Especial, set. 2015.CAMPANTE, Rubens Goyatá. O patrimonialismo em Faoro e Weber e a Sociologia brasileira. Dados - Revista de Ciências Sociais, Rio de Janeiro, Iuperj, v. 46, n. 1, p. 153-193, 2003.

CARdoso, Fernando Henrique. Pensadores que inventaram o Brasil. São Paulo: Companhia das Letras, 2013. 
Carvalho, José Murilo. A construção da ordem/ Teatro de Sombras. 2. ed. Rio de Janeiro: Relume Dumara, 1996.

Mandonismo, coronelismo, clientelismo: uma discussão conceitual. Dados

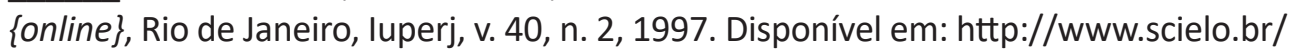
scielo.php?script=sci_arttext\&pid=S0011-52581997000200003\&lng=en\&nrm=iso.

CAstro Gomes, Ângela. A invenção do trabalhismo. São Paulo, Vértice, 1988.

DAMATTA, Roberto. Carnavais, malandros e heróis: para uma sociologia do dilema brasileiro. Rio de Janeiro: Zahar, 1980.

DolHNIKOFF, Miriam. O pacto imperial: origens do federalismo no Brasil. São Paulo: Globo, 2005.

FAORO, Raymundo. Os donos do poder. São Paulo: Globo, 2001.

FARIAS, Rogério de Souza. As origens diplomáticas da meritocracia: o papel do Itamaraty na criação do Dasp. Brasília: manuscrito, 2018. Disponível em: https:// www.researchgate.net/publication/323845505_As_origens_diplomaticas_da_ meritocracia_o_papel_do_Itamaraty_na_criacao_do_DASP?_

FebVRE, Lucien. Combats pour l'histoire. Paris: Armand Colin, 1953.

FILGUEIRAS, Fernando. Marcos teóricos da corrupção. In: Avritzer, L. et al. Corrupção: ensaios e crítica. Belo Horizonte: Editora UFMG, 2008. p. 353-361.

Guerreiro Ramos, a redução sociológica e o imaginário pós-colonial. Caderno CRH, Salvador, v. 25, n. 65, p. 347-363, mai./ago. 2012.

Fleıuss, Max. História administrativa do Brasil. 2. ed. São Paulo: Edições Melhoramentos, 1926.

GRAHAM, Richard. Clientelismo e política no Brasil do século XIX. Rio de Janeiro: UFRJ, 1997.

Guerreiro Ramos, Alberto. Administração e contexto brasileiro. Rio de Janeiro: Fundação Getúlio Vargas, 1983.

GUIMARÃES, Lúcia Maria Paschoal. Breves apontamentos para a história da administração pública. In: LUSTOSA DA COSTA, Frederico; ZAMOT, Fuad (Orgs.). Brasil: 200 anos de Estado, 200 anos de administração pública. Rio de Janeiro: Editora FGV, 2010.

JAGUARIBE, Helio. O nacionalismo na atualidade brasileira. Brasília: Funag, 2013.

LEAL, Victor Nunes. Coronelismo, enxada e voto. Rio de Janeiro: Nova Fronteira, 1997. LESSA, Renato. A invenção republicana: Campos Sales, as bases e a decadência da Primeira República Brasileira. 2. ed. Rio de Janeiro: Topbooks, 1999.

LUSTOSA DA COSTA, Frederico; LUSTOSA DA COSTA, Elza Marinho. Nova história da administração pública brasileira - pressupostos teóricos e fontes alternativos. Revista de Administração Pública, Rio de Janeiro, Fundação Getúlio Vargas, v. 50, n. 2, p. 215-236, mar./abr. 2016.

LUSTOSA DA COSTA, Frederico; ZAMOT, Fuad (Orgs.). Brasil: 200 anos de Estado, 200 anos de administração pública. Rio de Janeiro: Editora FGV, 2010.

LUSTOSA DA COSTA, Frederico. Preâmbulo a uma nova história da administração pública brasileira. In: LUSTOSA DA COSTA, Frederico; ZAMOT, Fuad (Orgs.). Brasil: 200 anos de Estado, 200 anos de administração pública. Rio de Janeiro: Editora FGV, 2010. 
LUSTOSA DA COSTA, Frederico. Relações Estado-sociedade no Brasil: representações para uso de reformadores. Dados, Rio de Janeiro, v. 52, n. 1, p. 161-199, mar. 2009. Disponível em: http://www.scielo.br/scielo.php?script=sci_arttext\&pid=S001152582009000100005\&lng=en\&nrm=iso.

http://dx.doi.org/10.1590/S001152582009000100005. Acesso em: 16 mai. 2018.

LUSTOSA DA COSTA, Frederico; O’DONNEL, Júlia; Mendes, Pedro Barbosa. 1808-2008

- Por uma nova história da administração pública brasileira. Revista do Instituto Histórico e Geográfico Brasileiro, Rio de Janeiro, IHGB, ano 170, n. 443, p. 287-312, abr./jun. 2009.

LUSTOSA DA COSTA, Frederico. 200 anos de Estado, 200 anos de administração pública, 200 anos de reformas. Revista de Administração Pública, Rio de Janeiro, Fundação Getúlio Vargas, v. 61, n. 3, p. 269-286, jul.-set. 2008.

. Estado, reforma do Estado e democracia no Brasil da Nova República. Revista de Administração Pública, Rio de Janeiro, Fundação Getúlio Vargas, v. 32, n. 4, p. 71-82, 1998.

MARE. Plano Diretor da Reforma do Aparelho do Estado. Brasília: Presidência da República, Imprensa Oficial, 1995.

MARTINS, Maria Fernanda Vieira. A velha arte de governar: um estudo sobre política e elites a partir do Conselho de Estado. Rio de Janeiro: Arquivo Nacional, 2007. MoRSE, RICHARD. O espelho de próspero. São Paulo, Companhia das Letras, 1988. Oliveira Júnior, T. M.; Lustosa dA Costa, Frederico; Mendes, Arnaldo Paulo. Perspectivas teóricas da corrupção no campo da administração pública brasileira: características, limites e alternativas. Revista do Serviço Público, v. 67, p. 111-138, 2016.

OliVEIRA TORRES, João Camilo. Interpretação da realidade brasileira. Rio de Janeiro: José Olympio, 1973.

Oliveira VianNA, Francisco José. Instituições políticas brasileiras. Brasília: Senado Federal, 1999.

PAIM, Antonio. A querela do estatismo. Rio de Janeiro: Tempo Brasileiro, 1978.

PANG, Eul-Soo. Coronelismo e oligarquias - 1989-1945. Rio de Janeiro: Civilização Brasileira, 1979.

PINHo, José Antônio Gomes de. Reforma do aparelho do Estado: limites do gerencialismo frente ao patrimonialismo. Organização \& Sociedade, Salvador, UFBA, v. 5, n. 12, p. 59-79, 1998.

Queiroz, Maria Isaura Pereira de. O mandonismo local na vida política brasileira e outros ensaios. São Paulo: Alfa-omega, 1976.

RIGGS, Fred W. A ecologia da administração pública. Rio de Janeiro: Fundação Getúlio Vargas, 1964.

RohlofF DE MATTOS, Ilmar. O tempo saquarema. 4. ed. Rio de Janeiro: ACCESS, 1999. SCHWARTZMAN, Simon. As bases do autoritarismo brasileiro. São Paulo: Campos, 1988. SFEZ, Lucien. La symbolique politique. Collection "Que sais-je?". Paris: PUF, 1988. SouzA, Jessé. A modernização seletiva: uma interpretação do dilema brasileiro. Brasília: Editora UnB, 2000. 
. A tolice da inteligência brasileira - ou como o país se deixa manipular pela elite. São Paulo: Leya, 2015.

URICOECHEA, Fernando. O minotauro imperial. A burocratização do Estado patrimonial brasileiro no século XIX. São Paulo: DIFEL, 1978.

VIEIRA, Clóvis Abreu; LUSTOSA DA COSTA; Frederico; BARBOSA, Lázaro André de Oliveira. O jeitinho brasileiro como um recurso de poder. Revista de Administração Pública, Rio de Janeiro, Fundação Getúlio Vargas, v. 16, n. 2, p. 5-31, abr./jun. 1982. VARNHAgen, Francisco Adolfo de. História geral do Brasil. São Paulo: Melhoramentos, 1956.

Vilaça, Marcos Vinícius; CaValcanti Albuquerque, Roberto. Coronel, coronéis. Rio de Janeiro: Tempo Brasileiro, 1965.

WAHRLICH, Beatriz Marques de Souza. Reforma administrativa federal brasileira: passado e presente, Revista de Administração Pública, v. 8, p. 27-75, 1974.

Weber, Max. Economia e sociedade. Brasília: Editora UnB, 1994. (Vol. I e II) . In: GeRTH, H. H.; Mills, C. Wright (Orgs.). Ensaios de Sociologia. Rio de Janeiro: Zahar, 1971.

WEFFORT, Francisco. O populismo na política brasileira. Rio de Janeiro: Paz e Terra, 1978.

WeHling, Arno; Wheling, Maria José. Direito e justiça no Brasil colonial - o Tribunal da Relação do Rio de Janeiro (1751-1808). 1. ed. Rio de Janeiro: Renovar, 2004.

É mestre em Administração Pública e Ciência Política e doutor em Gestão, pelo Instituto Superior de Ciências do Trabalho e da Empresa (ISCTE/IUL), Lisboa, Portugal. Atualmente é professor do Programa de Pós-graduação em Administração (PPGAd) da Universidade Federal Fluminense (UFF). Contato: fredericolustosa@id.uff.br 
RSP 